\title{
Correction to: Regional prevalence and determinants of exclusive breastfeeding in India
}

Felix Akpojene Ogbo ${ }^{1,2^{*}}$, Mansi Vijaybhai Dhami ${ }^{1}$, Akorede O. Awosemo², Bolajoko O. Olusanya ${ }^{3}$, Jacob Olusanya ${ }^{3}$, Uchechukwu L. Osuagwu ${ }^{4}$, Pramesh Raj Ghimire ${ }^{5}$, Andrew Page ${ }^{1}$ and Kingsley E. Agho ${ }^{5}$

\section{Correction to: International Breastfeeding Journal (2019) 14:20 DOI: 10.1186/s13006-019-0214-0}

Please note that in the original article [1], Fig. 1 was originally published with its figure legend erroneously omitted.

Please see below for the correct version of Fig. 1 (with its legend included):

The figure has been corrected in the original article.

The publisher apologizes for this processing error.

\begin{abstract}
Author details
${ }^{1}$ Translational Health Research Institute (THRI), School of Medicine, Western Sydney University, Campbelltown Campus, Locked Bag 1797, Penrith, NSW 2571, Australia. ${ }^{2}$ Prescot Specialist Medical Centre, Welfare Quarters, Makurdi, Benue State, Nigeria. ${ }^{3}$ Centre for Healthy Start Initiative, 286A Corporation Drive, Dolphin Estate, Ikoyi, Lagos, Nigeria. ${ }^{4}$ School of Medicine | Diabetes Obesity and Metabolism Translational Research Unit (DOMTRU), Macarthur Clinical School, Parkside Crescent, Campbelltown, NSW 2560, Australia.

${ }^{5}$ School of Science and Health, Western Sydney University, Campbelltown Campus, Locked Bag 1797, Penrith, NSW 2571, Australia.
\end{abstract}

Published online: 04 June 2019

\section{Reference}

1. Ogbo FA, et al. Regional prevalence and determinants of exclusive

breastfeeding in India. Int Breastfeed J. 2019;14:20.

https://doi.org/10.1186/s13006-019-0214-0.

\footnotetext{
* Correspondence: felgbo@yahoo.co.uk; f.ogbo@westernsydney.edu.au

${ }^{1}$ Translational Health Research Institute (THRI), School of Medicine, Western Sydney University, Campbelltown Campus, Locked Bag 1797, Penrith, NSW 2571, Australia

${ }_{2}^{2}$ Prescot Specialist Medical Centre, Welfare Quarters, Makurdi, Benue State,

Nigeria

Full list of author information is available at the end of the article
}

(c) The Author(s). 2019 Open Access This article is distributed under the terms of the Creative Commons Attribution 4.0 International License (http://creativecommons.org/licenses/by/4.0/), which permits unrestricted use, distribution, and reproduction in any medium, provided you give appropriate credit to the original author(s) and the source, provide a link to the Creative Commons license, and indicate if changes were made. The Creative Commons Public Domain Dedication waiver (http://creativecommons.org/publicdomain/zero/1.0/) applies to the data made available in this article, unless otherwise stated. 


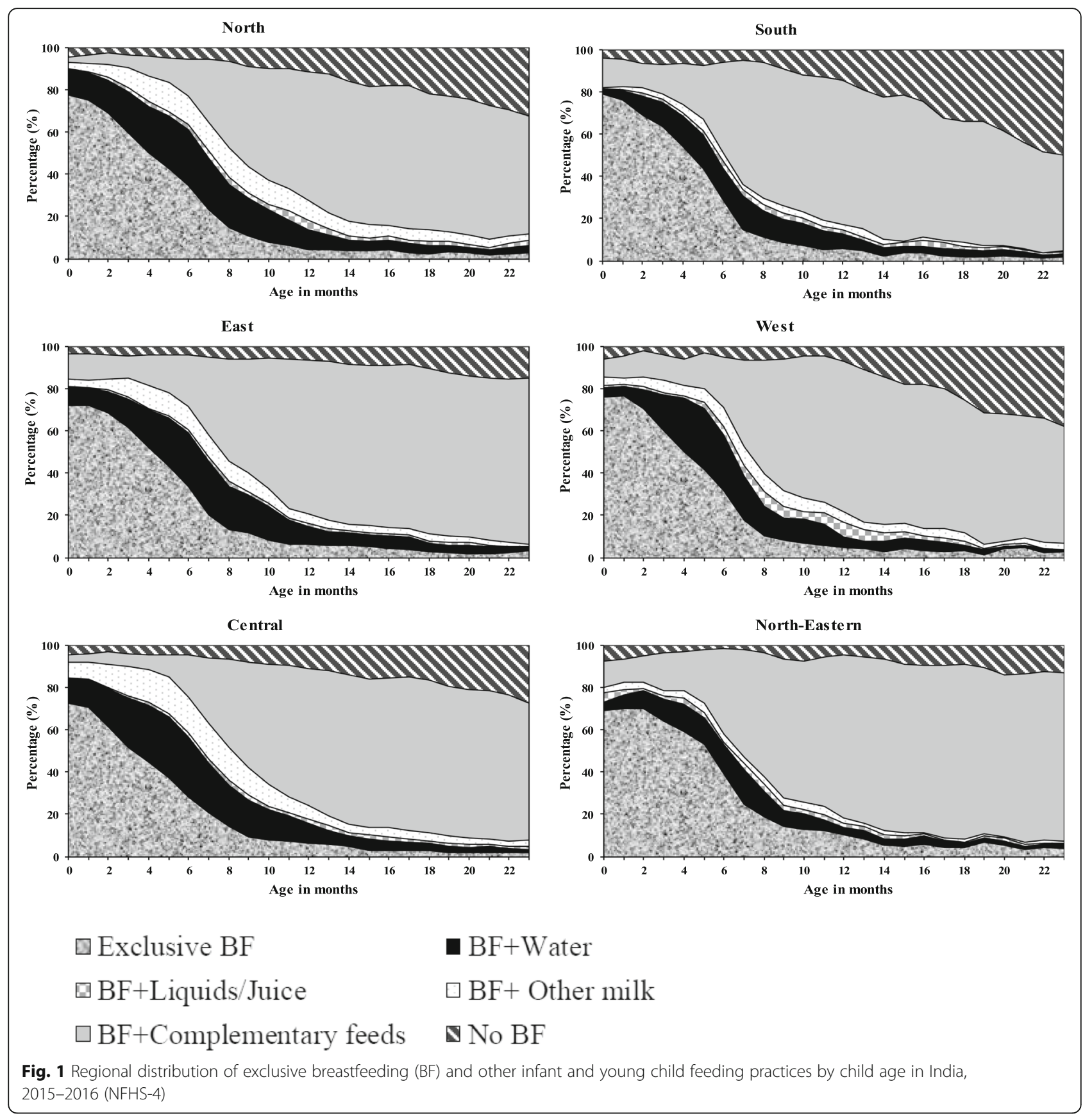

